\title{
Activity Coefficient of Polyelectrolytes in the Ternary System Water-Sodium Polyvinyl Sulfate-Sodium Chloride*
}

\author{
Fumio Matsui, Norio IsE, ${ }^{* *}$ and Tsuneo OKuBo \\ Department of Polymer Chemistry, Kyoto University, Kyoto, Japan.
}

(Received July 16, 1969)

\begin{abstract}
Isopiestic vapor pressure measurements were carried out for the ternary system water-sodium polyvinyl sulfate-sodium chloride. The variation of the isopiestic ratio with the concentration fraction of an electrolyte component is as large as that for watersodium polyacrylate-sodium chloride. The mean activity coefficients of sodium polyvinyl sulfate and sodium chloride were obtained. The activity coefficient of the polyelectrolyte increases with polymer concentration. It decreases with increasing simple electrolyte concentration and through a minimum increases. The activity coefficient of sodium chloride decreases with its own concentration, obeying the cube-root rule. The presence of the polyelectrolyte enlarges the range of fit of the rule. The activity coefficient of sodium chloride decreases at first with increasing polymer concentration and then increases when the simple electrolyte concentration is low, whereas it increases monotonously with polymer concentration for high simple electrolyte concentrations. These results are compared with those previously obtained for the sodium polyacrylate system.
\end{abstract}

KEY WORDS Sodium Chloride / Sodium Polyvinyl Sulfate / Mean Activity Coefficient / Isopiestic Measurements / Cube-Root Rule / Intermacroion Linkage /

In one of our recent studies on the activity coefficient of polyelectrolytes, isopiestic measurements were performed on a ternary system watersodium polyacrylate-sodium chloride. ${ }^{1}$ The results were compared with those obtained by an independent method in terms of the second virial coefficient. With the present scarcity of this type of information, this success urged us to extend measurements to other ternary systems. In this paper we report the activity coefficient data of sodium polyvinyl sulfate (NaPVAS) and $\mathrm{NaCl}$ in the ternary system $\mathrm{H}_{2} \mathrm{O}-\mathrm{NaPVAS}-\mathrm{NaCl}$. The NaPVAS was used for previous measurements on the binary system water-NaPVAS. ${ }^{2}$ It should be understood, however, that the present work forms only part of our research project, in which we intend to carry out basic thermodynamic analyses of various types of interactions in polyelectrolyte solutions. It is hoped that in the near future data can be reported for ternary systems of polyelectrolytes having various (linear)

* This is Part VII of "Mean Activity Coefficient of Polyelectrolytes".

** To whom correspondence should be addressed. charge densities, and various types of ionizable groups and gegenions.

It seems necessary to make mention here of the following. In the present and subsequent papers, the term "mean" modifying "activity coefficient of polyelectrolytes" is not and will not be used. As has been clearly demonstrated, ${ }^{3}$ the theory of liquid junction does not apply to polyelectrolyte solutions, particularly when highly charged. Therefore, the single-ion activity coefficients of macroions and of their gegenions, having no physical significance, are irrelevant from the experimental point of view. Thus, our attention will be focused exclusively on the mean activity coefficient unless otherwise specified, and hence the use of this adjective will not be necessary.

\section{EXPERIMENTAL}

An aqueous solution of NaPVAS (a product of the Seiko Chemical Co., Fukuoka, Japan) was passed through columns of cation- and anionexchange resins, and then neutralized with an aqueous solution of sodium hydroxide as soon as possible, with the aid of potentiometric titration 


\section{Activity Coefficient of Polyelectrolytes}

in order to prevent the acid saponification. The degree of neutralization was 1.00 . The degree of polymerization of the parent polyvinyl alcohol was 1700 in viscometry. The degree of esterification was $0.22_{7}$, determined by both the titration method and sulfur analysis.

Details of the apparatus used and the experimental procedure have already been described. ${ }^{1}$ The accuracy of the present measurements was at the highest $2.5 \%$. The measurements were carried out at $25^{\circ} \mathrm{C}$ and at total ionic concentrations higher than 0.15 .

\section{RESULTS AND DISCUSSION}

The activity coefficients of NaPVAS and $\mathrm{NaCl}$ in the ternary system ( $\gamma_{2}$ and $\gamma_{3}$, respectively) were calculated using the McKay-Perring relations. ${ }^{4}$ To save space, the relations and notations used for the calculation will not be given here; they should be referred to in the previous work. ${ }^{1 \prime}$ We have taken a figure 0.43 for the value of the polymer charge fraction $\beta$, or the net valency of a macroion divided by the stoichiometric valency. This value was originally obtained by transference experiments for a sodium polyacrylate at a degree of neutralization of 1.0..$^{5}$ Though the NaPVAS

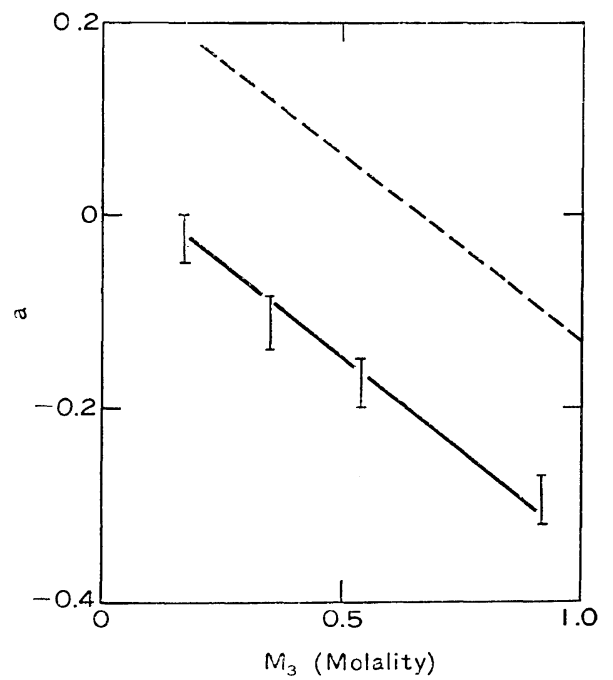

(a) has a much lower linear charge density than the polyacrylate, it might be expected that gegenions are associated with the polysulfate ions to approximately the same extent as the carboxylate ions, on the basis of existing data that the $\beta$ value is not sensitive toward the charge density, even more so when the latter is high. In order to facilitate comparison between these two kinds of polyelectrolytes, therefore we develop our discussion with $\beta=0.43$.

The results of the isopiestic measurements are given in Table I. The observed concentrations of NaPVAS $\left(\mathrm{m}_{2}\right)$ and $\mathrm{NaCl}\left(\mathrm{m}_{3}\right)$ in isopiestic equilibrium with binary solutions of $\mathrm{H}_{2} \mathrm{O}-\mathrm{NaPVAS}$ $\left(\mathrm{M}_{2}\right)$ and $\mathrm{H}_{2} \mathrm{O}-\mathrm{NaCl}\left(\mathrm{M}_{3}\right)$ are given in the second and third columns, respectively. The fourth column gives the polymer ionic fraction $x$ and the fifth the isopiestic ratio $R$. The $R$ values are found to be adequately represented by $R=1-$ $a x-b x^{2}$, where $a$ and $b$ are constants. In Figure 1, these constants are plotted against $\mathbf{M}_{3}$. For comparison, the results for NaPAA are also given, indicated by dotted lines. We note that $a$ and $b$ for NaPVAS decrease with increasing $M_{3}$ as sharply as those for NaPAA, though there is a considerable difference in the linear charge density.

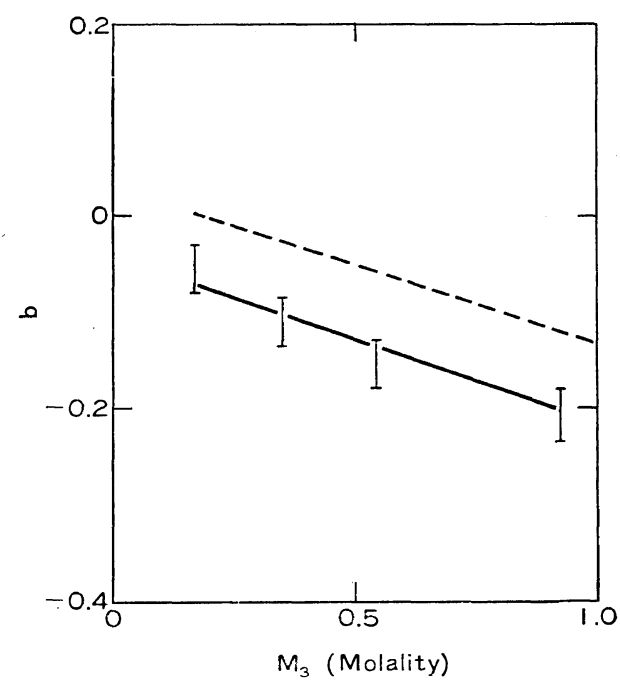

(b)

Figure 1. The constants of the equation $R=1-a x-b x^{2}$.

- I - : $\mathrm{H}_{2} \mathrm{O}-\mathrm{NaPVAS}-\mathrm{NaCl}$

$\ldots \ldots \ldots$ : $\mathrm{H}_{2} \mathrm{O}-\mathrm{NaPAA}-\mathrm{NaCl}$ taken from the work cited in ref. 1 . 
F. Matsui, N. Ise, and T. OKubo

Table I. Isopiestic data of the ternary system $\mathrm{H}_{2} \mathrm{O}-\mathrm{NaPVAS}-\mathrm{NaCl}$ at $25^{\circ} \mathrm{C}$

\begin{tabular}{|c|c|c|c|c|c|c|}
\hline Set & $\begin{array}{c}\mathrm{m}_{2} \\
\text { (equiv/1000 } \mathrm{g} \\
\text { of water) }\end{array}$ & $\underset{\text { (Molality) }}{\mathrm{m}_{3}}$ & $x$ & $R$ & $\log \gamma 2^{a}$ & $\log \gamma_{3}$ \\
\hline \multirow{8}{*}{1} & 0 & $0.165\left(\mathrm{M}_{3}\right)$ & 0 & 1.00 & -0.286 & $-0.12_{8}$ \\
\hline & 0.0211 & 0.164 & 0.027 & 0.98 & $-0.29_{2}$ & $-0.13_{5}$ \\
\hline & 0.0999 & 0.141 & 0.132 & 1.02 & $-0.27_{3}$ & $-0.12_{1}$ \\
\hline & 0.127 & 0.136 & 0.167 & 1.01 & $-0.27_{5}$ & $-0.12_{4}$ \\
\hline & 0.179 & 0.126 & 0.233 & 1.00 & $-0.26_{9}$ & $-0.13_{1}$ \\
\hline & 0.406 & 0.0725 & 0.546 & 1.03 & $-0.25_{2}$ & $-0.12_{0}$ \\
\hline & 0.485 & 0.0566 & 0.648 & 1.03 & $-0.25_{3}$ & $-0.12_{7}$ \\
\hline & $0.700\left(\mathrm{M}_{2}\right)$ & 0 & 1.000 & 1.08 & $\begin{array}{l}-0.22_{1} \\
\left(\log \Gamma_{2}\right)\end{array}$ & $-0.11_{9}$ \\
\hline \multirow{10}{*}{2} & 0 & $0.349\left(\mathrm{M}_{3}\right)$ & 0 & 1.00 & $-0.30_{0}$ & $-0.15_{5}$ \\
\hline & 0.0434 & 0.336 & 0.027 & 1.01 & $-0.29_{3}$ & $-0.15_{0}$ \\
\hline & 0.0835 & 0.325 & 0.052 & 1.02 & $-0.28_{8}$ & $-0.14_{7}$ \\
\hline & 0.366 & 0.258 & 0.233 & 1.04 & $-0.26_{5}$ & $-0.14_{2}$ \\
\hline & 0.578 & 0.209 & 0.373 & 1.05 & $-0.25_{0}$ & $-0.14_{1}$ \\
\hline & 0.648 & 0.181 & 0.436 & 1.09 & $-0.22_{9}$ & -0.12 \\
\hline & 0.813 & 0.145 & 0.546 & 1.09 & $-0.22_{3}$ & $-0.13_{1}$ \\
\hline & 0.957 & 0.113 & 0.646 & 1.10 & $-0.21_{7}$ & $-0.13_{5}$ \\
\hline & 1.09 & 0.0686 & 0.773 & 1.16 & $-0.19_{1}$ & $-0.12_{1}$ \\
\hline & $1.33\left(\mathrm{M}_{2}\right)$ & 0 & 1.000 & 1.22 & $\begin{array}{l}-0.16_{5} \\
\left(\log \Gamma_{2}\right)\end{array}$ & $-0.11_{7}$ \\
\hline \multirow{11}{*}{3} & 0 & $0.536\left(\mathrm{M}_{3}\right)$ & 0 & 1.00 & $-0.30_{1}$ & $-0.16_{9}$ \\
\hline & 0.0668 & 0.517 & 0.027 & 1.01 & $-0.29_{3}$ & $-0.16_{6}$ \\
\hline & 0.128 & 0.494 & 0.053 & 1.03 & $-0.28_{1}$ & $-0.15_{8}$ \\
\hline & 0.319 & 0.451 & 0.132 & 1.03 & $-0.26_{9}$ & $-0.15_{7}$ \\
\hline & 0.405 & 0.433 & 0.167 & 1.03 & $-0.26_{6}$ & $-0.15_{9}$ \\
\hline & 0.543 & 0.384 & 0.233 & 1.07 & $-0.24_{2}$ & $-0.14_{4}$ \\
\hline & 0.972 & 0.271 & 0.436 & 1.12 & $-0.20_{3}$ & $-0.13_{5}$ \\
\hline & 1.18 & 0.211 & 0.546 & 1.15 & $-0.18_{2}$ & -0.129 \\
\hline & 1.37 & 0.159 & 0.649 & 1.18 & $-0.16_{4}$ & $-0.12_{8}$ \\
\hline & 1.55 & 0.0982 & 0.773 & 1.24 & $-0.13_{9}$ & $-0.11_{9}$ \\
\hline & $1.89\left(\mathrm{M}_{2}\right)$ & 0 & 1.000 & 1.32 & $\begin{array}{l}-0.10_{9} \\
\left(\log \Gamma_{2}\right)\end{array}$ & $-0.12_{1}$ \\
\hline \multirow{11}{*}{4} & 0 & $0.921\left(\mathrm{M}_{3}\right)$ & 0 & 1.00 & $-0.28_{3}$ & $-0.18_{2}$ \\
\hline & 0.116 & 0.896 & 0.027 & 1.00 & $-0.27_{7}$ & $-0.18_{2}$ \\
\hline & 0.212 & 0.825 & 0.052 & 1.04 & $-0.26_{6}$ & $-0.16_{7}$ \\
\hline & 0.543 & 0.768 & 0.132 & 1.04 & $-0.23_{8}$ & $-0.16_{6}$ \\
\hline & 0.678 & 0.726 & 0.167 & 1.03 & $-0.24_{3}$ & $-0.17_{0}$ \\
\hline & 0.901 & 0.638 & 0.233 & 1.11 & $-0.19_{2}$ & $-0.14_{3}$ \\
\hline & 1.58 & 0.439 & 0.436 & 1.18 & $-0.13_{3}$ & $-0.13_{0}$ \\
\hline & 1.88 & 0.335 & 0.546 & 1.25 & $-0.09_{8}$ & $-0.12_{0}$ \\
\hline & 2.16 & 0.252 & 0.648 & 1.28 & $-0.07_{6}$ & $-0.12_{0}$ \\
\hline & 2.45 & 0.155 & 0.773 & 1.35 & $-0.04_{6}$ & $-0.11_{9}$ \\
\hline & $2.89\left(\mathrm{M}_{2}\right)$ & 0 & 1.000 & 1.48 & $\begin{array}{c}0 \\
\left(\log \Gamma_{2}\right)\end{array}$ & $-0.12_{4}$ \\
\hline
\end{tabular}

a The activity coefficient of NaPVAS at $\mathrm{M}_{2}=2.89$ in the binary system water-NaPVAS was chosen as unity. 


\section{Activity Coefficient of Polyelectrolytes}

The activity coefficient $\left(\Gamma_{2}\right)$ of NaPVAS in the binary solution was obtained from the condition of equal vapor pressure, ${ }^{6}$ as previously described. ${ }^{1}$ Using the $\Gamma_{2}$ value, the activity coefficient of $\mathrm{NaCl}$ in the binary solution $\left(\Gamma_{3}\right),{ }^{7}$ the isopiestic ratio, and the $b$ value, one obtains $\log \gamma_{2}$ and $\log$ $\gamma_{3}$ given in the sixth and seventh columns of Table I, respectively.

$\log \gamma_{2}$ at constant $\mathrm{m}_{3}$ can be obtained as a function of $\mathrm{m}_{2}$ from the data given in Table I. The result is shown in Figures 2(a) and (b). It can be seen that $\log \gamma_{2}$ increases monotonously with increasing $\mathrm{m}_{2}$. According to our observation on $\mathrm{H}_{2} \mathrm{O}$-sodium polyacrylate (NaPAA)- $\mathrm{NaCl},{ }^{1}$ $\log \gamma_{2}$ first decreased linearly with the cube-root of $\mathrm{m}_{2}$ when $\mathrm{m}_{3}$ is smaller than 0.50 . Clearly, Figure 2 shows that the cube-root rule does not hold for $\gamma_{2}$ of NaPVAS in the studied range of $\mathrm{NaCl}$ concentrations. This is due to the difference in the charge density of these two polyelectrolytes; the electrostatic interaction between sodium ions and PVAS ions is not strong enough to overcome the non-electrostatic interaction so that the cuberoot rule is no longer valid in the concentration range studied.

It should further be noted that at small $\mathrm{m}_{2}$,

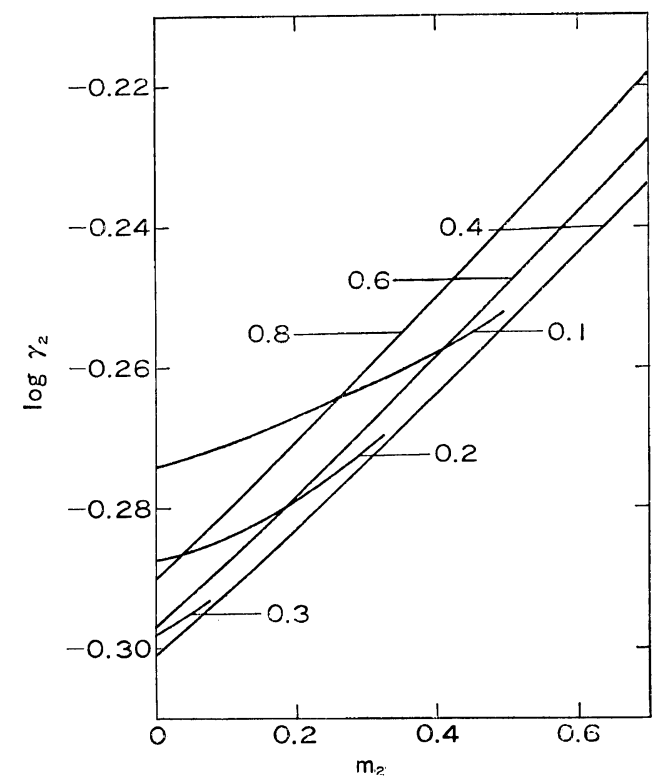

(a) $\log \gamma_{2}$ decreases at first with increasing $\mathrm{m}_{2}$ (Table I, Set 1) and then increases, as was also previously found for small $\mathrm{m}_{2}$ in the ternary system $\mathrm{H}_{2} \mathrm{O}$ NaPAA- $\mathrm{NaCl}$ (See Figure 4 in ref. 1). This concentration dependence indicates that an addition of simple electrolyte results in a rise of the gegenion concentration in the vicinity of the macroions and strengthens the intermacroion linkage ${ }^{8}$ when the concentration of simple electrolyte is relatively low, whereas the presence of large amounts of simple electrolyte causes a shielding effect which weakens the linkage.

$\log \gamma_{3}$ is given at constant $m_{3}$ as a function of $\mathrm{m}_{2}$ in Figure 3. It is observed that $\log \gamma_{3}$ has a minimum for $\mathrm{m}_{3}<0.3$ whereas it steadily increases for large $\mathrm{m}_{3}$. This is in qualitative agreement with our previous observation with $\mathrm{H}_{2} \mathrm{O}$ NaPAA- $\mathrm{NaCl}$ found at low concentrations of $\mathrm{NaCl}$ and NaPAA (See Figure 5 in ref. 1). The present observation in Figure 3 that $\log \gamma_{3}$ decreased with rising $\mathrm{m}_{3}$ at constant $\mathrm{m}_{2}$, however, was found also for $\mathrm{H}_{2} \mathrm{O}-\mathrm{NaPAA}-\mathrm{NaCl}$, only when $\mathrm{m}_{2}$ and $\mathrm{m}_{3}$ were low. This difference can again be attributed to the low charge density of NaPVAS.

Figure 4 shows $\log \gamma_{3}$ at constant $\mathrm{m}_{2}$ as a function of the cube-root of simple electrolyte con-

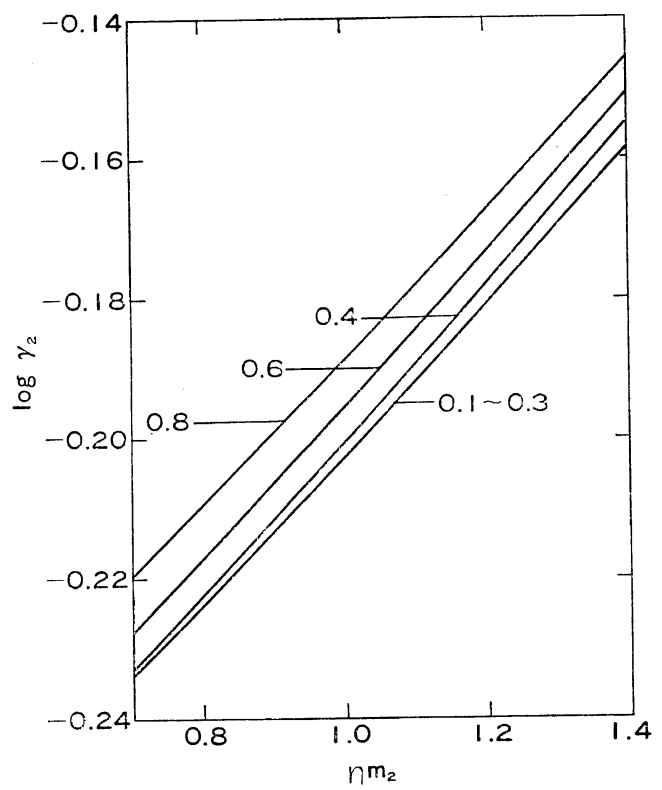

(b)

Figure 2. Activity coefficient of NaPVAS in the ternary system $\mathrm{H}_{2} \mathrm{O}-\mathrm{NaPVAS}-\mathrm{NaCl}$ as a function of the polymer concentration $\left(25^{\circ} \mathrm{C}\right)$. 


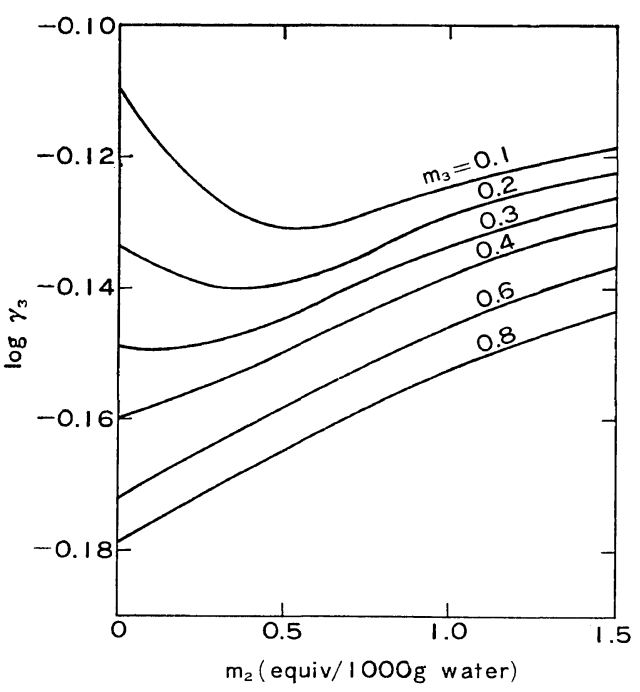

Figure 3. Activity coefficient of $\mathrm{NaCl}$ in the ternary system $\mathrm{H}_{2} \mathrm{O}-\mathrm{NaPVAS}-\mathrm{NaCl}$ as a function of the polymer concentration $\left(25^{\circ} \mathrm{C}\right)$.

centration. (The plot for $\mathrm{m}_{2}=0$ was obtained by using the values reported in the literature. ${ }^{7}$ It is seen that the cube-root rule holds for a fairly wide range of concentrations so far as low

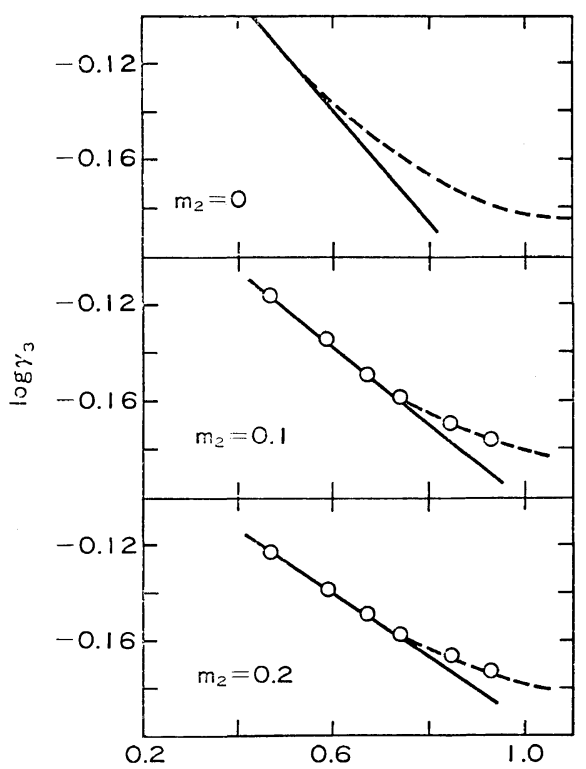

polymer concentrations are concerned. In Table II, the slope of the plot and the upper limit of the rule were tabulated. It should be noted that the magnitude of the slope decreases and the limit shifts toward higher $m_{3}$ with increasing polymer concentration. As is well known, the cube-root relation on the concentration dependence of mean activity coefficient was earlier noted by Frank and Thompson, ${ }^{9}$ and Robinson and Stokes $^{10}$ for low molecular weight electrolytes, and was attributed to locally regular distribution of ionic

Table II. The constants of the cube-root plot of $\log \gamma_{3}$

\begin{tabular}{cll}
\hline $\begin{array}{c}\mathrm{m}_{2} \\
\text { (equiv/1000 g } \\
\text { of water) }\end{array}$ & $\begin{array}{c}\text { Upper limit } \\
\text { (equiv/1000 } \mathrm{g} \\
\text { of water) }\end{array}$ & \multicolumn{1}{c}{ Slope } \\
\hline 0 & 0.11 & -0.26 \\
0.10 & $0.42(0.51)^{\mathrm{a}}$ & $-0.16(-0.11)^{\mathrm{a}}$ \\
0.20 & 0.42 & -0.13 \\
0.30 & $0.62(0.73)^{\mathrm{a}}$ & $-0.10(-0.06)^{\mathrm{a}}$ \\
0.40 & $>0.86$ & -0.08 \\
0.60 & $>0.86$ & -0.06
\end{tabular}

a Data of $\mathrm{H}_{2} \mathrm{O}-\mathrm{NaPAA}-\mathrm{NaCl}$ reported by $\mathrm{T}$. Okubo, N. Ise, and F. Matsui, J. Amer. Chem. Soc., 89, 3697 (1967).

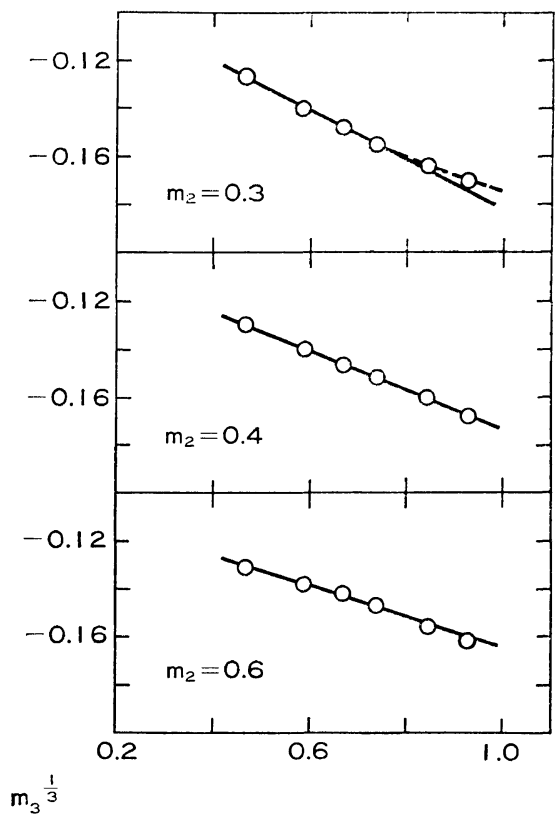

Figure 4. Cube-root plots of the activity coefficient of $\mathrm{NaCl}$ in the ternary system $\mathrm{H}_{2} \mathrm{O}-\mathrm{NaPVAS}-$ $\mathrm{NaCl}\left(25^{\circ} \mathrm{C}\right)$. 
species. The present results thus suggest that the local regularity in the distribution of simple electrolyte ions is largely enhanced by the presence of the polyelectrolyte. It would be readily admitted that the negatively charged macroions attract strongly the positively charged simple electrolyte ions so that the former act as a "rallying" point. Thusan "intersimpleion" linkage can be formed through the intermediary of macroions, in addition to the "intermacroion" linkage previously mentioned. ${ }^{8}$ In this respect, we should note that the presence of such a linkage in solutions was also claimed in the light of viscoelastic data by Eisenberg, Saito and Teter. ${ }^{11}$ These authors found that the time-temperature superposition is not applicable for the stress relaxation curves of lanthanum-doped sodium polyphosphate, and inferred that the polymer relaxes by two mechanisms, namely, "bond interchange" and normal diffusion motion. It seems to us that Eisenberg et al. and we say the same thing but in different languages. Furthermore, Wall and Drenan $^{12}$ concluded earlier from viscosity data that a linkage existed and Butler et $a l^{13}$ treated the problem theoretically.

Since intersimple ion linkage could be suggested for NaPVAS of a low charge density, we might also expect the linkage to be found in the case of NaPAA of a high charge density. Figure 5 shows the cube-root plot of $\log \gamma_{3}$ reported previously for $\mathrm{H}_{2} \mathrm{O}-\mathrm{NaPAA}-\mathrm{NaCl}^{1}{ }^{1}$ Clearly, the cube-root rule is valid for $\mathrm{m}_{2}<0.5$. The slope and upper limit are given in parentheses in Table II. The differences between NaPVAS and NaPAA are insignificant. Thus, the charge density is regarded as not very influential so far as polyelectrolyte-simple electrolyte interaction is concerned.

A further comment should be made on interionic linkage. The presence of the linkage is expected to exert an influence on reactions between ions, even more strongly by the coexistence of polyelectrolytes. It was found in the 1930's that reactions between likely charged ionic species were enhanced by increasing ionic strength (the primary salt effect). ${ }^{14}$ Recently it was established that the primary salt effect was very great if synthetic polyelectrolytes were used. ${ }^{15,16}$ Significant acceleration effects were also observed by us for DNA, RNA and their related poly-

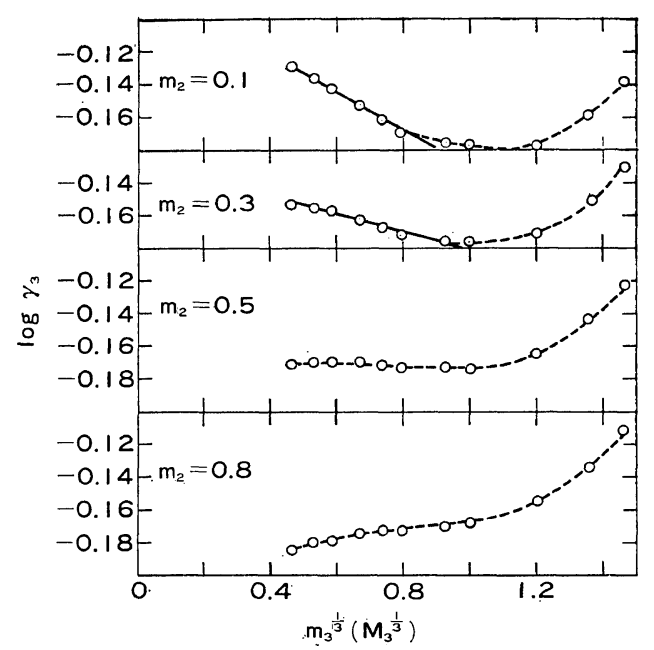

Figure 5. Cube-root plots of the activity coefficient of $\mathrm{NaCl}$ in the ternary system $\mathrm{H}_{2} \mathrm{O}-\mathrm{NaPAA}-\mathrm{NaCl}$ $\left(25^{\circ} \mathrm{C}\right)$.

Taken from the work cited in ref. 1 .

nucleotides $^{17}$, and for the E2 reaction of halomaleate or halofumarate. ${ }^{18}$

Acknowledgment. Sincere thanks are due to Prof. I. Sakurada for his encouragement.

\section{REFERENCES}

1. T. Okubo, N. Ise, and F. Matsui, J. Amer. Chem. Soc., 89, 3697 (1967).

2. N. Ise and T. Okubo, J. Phys. Chem., 71, 1886 (1967).

3. N. Ise and T. Okubo, J. Phys. Chem., 70, 2407 (1966).

4. H. A. C. McKay and J. K. Perring, Trans. Faraday Soc., 49, 163 (1933).

5. T. Okubo, T. Nishizaki, and N. Ise, J. Phys. Chem., 69, 3690 (1965).

6. It was found that the activity coefficients of NaPVAS in the binary solutions given in Table I are not in agreement with those published previously (ref. 2). This may be due to saponification of the polymeric ester which takes place easily in the preparation process of the solution. Thus the previous data were not used in the present calculation of $\gamma_{2}$.

7. A.S. Brown and D.A. MacInnes, J. Amer. Chem. Soc., 57, 1356 (1935); R. H. Stokes and B. J. Levien, ibid., 68, 333 (1946).

8. N. Ise and T. Okubo, J. Phys. Chem., 70, 1930 (1966). 
9. H.S. Frank and P. T. Thompson, J. Chem. Phys., 31, 1086 (1958).

10. R. A. Robinson and R. H. Stokes, "Electrolyte Solutions", Butterworth and Co. Ltd., London, 1959, Chapter 9.

11. A. Eisenberg, S. Saito, and L. Teter, J. Polym. Sci., Part C, No. 14, 323 (1966).

12. F. T. Wall and J. W. Drenan, J. Polym. Sci., 7, 83 (1951).

13. J. A. V. Butler, B. E. Conway, and D. W. F.
James, Trans. Faraday Soc., 50, 612 (1954).

14. See textbook of physical chemistry, for example, W. J. Moore, "Physical Chemistry" PrenticeHall, N. J., 1962, p. 369.

15. N. Ise and F. Matsui, J. Amer. Chem. Soc., 90, 4242 (1968).

16. H. Morawetz and B. Vogel, ibid., 91, 563 (1969).

17. N. Ise, Nature in press.

18. T. Ueda, S. Harada, and N. Ise, to be published. 